\title{
Study on the Impacts of Patent Cooperation Network in University-Industry-Research Collaboration upon the Innovation Performance of University
}

\author{
Xiaoqing Zhao ${ }^{1, a}$, WeipengLi $i^{2, b}$, Li Zhou ${ }^{3, c}$ \\ ${ }^{1}$ Graduate Department, Beijing Wuzi University, Beijing, China \\ ${ }^{2}$ Graduate Department, Beijing Wuzi University, Beijing, China \\ ${ }^{3}$ School of Information, Beijing Wuzi University, Beijing, China

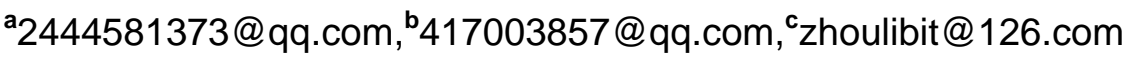

\begin{abstract}
Keywords: university-industry-research collaboration; patent cooperation network; innovation performance
\end{abstract}

\begin{abstract}
In university-industry-research collaborative projects, patent cooperation network building and sustaining played an important role, promoting the communication, transfer and share knowledge among universities, scientific research institutions and industry, promoting the effective use of resources, and promoting the improve of innovation ability of colleges and universities. It is worthy of our in-depth discussion what the characteristics and harvest of universities in theuniversity-industry-research collaboration process in Zhejiang, the eastern region more developed on education and economy. Therefore, we select 10 universities in Zhejiang province as the research object, the patent applied by universities and enterprises jointly and applied by universities and research institutions as the starting point to carry on the analysis of cooperation depth, cooperation breadth and network density of the patent cooperation network centering on university in Zhejiang, and further analyze the influence of patent cooperation network in university-industry-research collaboration on innovation performance of colleges and universities empirically through SPSS to make suggestions for universities’ development.
\end{abstract}

\section{Introduction}

With the knowledge economy era coming, the key role of innovation for a country growing has received wide recognition. As a cluster of knowledge and talents, colleges are the backbone of the construction of an innovative country, for it takes responsibilities of scientific and technological innovation, talents training, knowledge spreading, and other important missions. Today, the market is changing rapidly and technology is upgrading constantly, so colleges and universities have to depend on external strength to achieve innovation breakthrough. It becomes the key to realizing the innovation goal in the product or service whether colleges can combine innovative resources between the internal and the external organically.University-industry-research collaboration complies with the requirement of raising innovation ability in the new era to become an effective means of realizing the innovation goal. In university-industry-research collaborative projects, building and sustaining patent cooperation network play an important role, promoting the knowledge share and transfer among universities, research institutions and industries, promoting the effective use of resources, and promoting the improve of universities' innovation ability.

At the present, theresearch on patent cooperation network is mainly concentrated in the effect of enterprise innovation performance and enterprise productivity, while the study of the impact of patent cooperation network on university innovation performance is less. Yoo - Jin Han and Yongtae Park provided an exploratory way to measure knowledge liquidity among enterprises on the basis of patent analysis and input-output analysis in South Korea, and found that some weak ties and missing links made knowledge networks still incomplete. [1] On the basis of an original investigation about doctor's work history in the physical sciences and engineering, Hsing-fen Lee, Marcela Miozzo found subjects which doctor conducts with company are more likely to be committed to solve specific technical problems, or to promote the development of the company 
specifications and specification, rather than to explore the main risky things or to generate new knowledge in the new field by using multivariate probability analysis and linear analysis method and the resampling change estimation technology [2].CHRISTIAN STERNITZKE found a way of international patent protection is applying for patents by patent cooperation contract [3].Sam Mil 'shteinput forward participating in joint research projects with industry company is conducive to strengthen and improve their own innovation ability through discussion about specific skills needed by undergraduate and graduate students at the Massachusetts institute [4].

In this paper, we select 10 universities in Zhejiang province---China Jiliang University, Zhejiang Sci-Tech University, Zhejiang Gongshang University, Hangzhou Electronic Science and Technology University, Zhejiang University of Technology, Zhejiang University of Science and Technology, Ningbo University, Zhejiang A\&F University, Wenzhou Medical College, Zhejiang Chinese Medical University as research objects, which are all in the top 20 in the Zhejiang rankings of "Chinese universities evaluation study in 2016" complied by China alumni network, are the main undergraduate colleges in Zhejiang province, and whose abilities of scientific research and social service are relatively average levels, having certain comparability. Then, we analyze the ten universities' cooperation depth, breadth and network density in the patent cooperation network through Ucinet. Finally, we analyze the influence of cooperation depth, breadth and network density of patent cooperation network on universities' innovation performance and offer some suggestions to universities.

\section{Analysis of patent cooperation network centering on university in the Zhejiang province}

This chapter mainly analyzes university-industry-research patent cooperation network from three aspects including cooperation depth, cooperation breadth and network densityin Zhejiang province.

The cooperation depth of patent cooperation network is reflected quantificationally by the thickness of network linesand the quantity of thick lines, sayingthe average numbers of patents applied byan off-campus organizationand the university jointly.The cooperation breadth is reflected quantificationally by the network node number, saying the numbers of institutions cooperated with the university.[5]

The greater network density is, the closer the connectionsamong members of the network are, and the largerimpacts ofnetwork onattitude, behavior of actors are.The interconnected network provides the individual with rich social resources.

In the Ucinet software, network density is the ratio betweenthe actual number of connectionsamong network nodes and the maximumnumber of connections theoretically. We can compute Network Density using the path Network $\longrightarrow$ Cohesion $\longrightarrow$ Densityin the Ucinet software.

We collect the scores of innovation performance of ten universities in Zhejiang in 2013 by searching many resources. [6]

It can be seen from the table 1 that at present the number of institutions cooperating with universities is few, whose mean value is twelve.So the universities should strengthen the cooperation with enterprises and research institutions, and should actively look for the right cooperation organization to contribute to cooperation.In addition, the average number of patents applied by universities with an off campus organization jointly is less, only Wenzhou Medical College close to 2, the rest all less than 1.6.So the universities should actively deepen cooperation with the external institutions. The density of the rest universitiesare similar, small, all less than 0.35 , reflecting that the relationship among members of patent cooperation network centering universities is not strong.Therefore, it is suggested that colleges and universities should actively maintain theirpatent cooperation network, strengthen cooperation withmore and more institutions such as enterprise, scientific research institution and other universitiesto develop patents to make effective use of social resources to promote the improve of the institutional innovativeability to realize the goal of the construction of an innovative country. 
Table 1 related data collection of ten universities in Zhejiang

\begin{tabular}{|c|c|c|c|c|}
\hline university & $\begin{array}{c}\text { Cooperation } \\
\text { depth }\end{array}$ & $\begin{array}{c}\text { Cooperation } \\
\text { breadth }\end{array}$ & $\begin{array}{c}\text { Network } \\
\text { density }\end{array}$ & $\begin{array}{c}\text { Score of } \\
\text { innovation } \\
\text { performance }\end{array}$ \\
\hline China Jiliang University & 1.4 & 10 & 0.2314 & 33.17 \\
\hline Zhejiang Sci-Tech University & 1.412 & 17 & 0.1895 & 55.85 \\
\hline Zhejiang Gongshang University & 1 & 11 & 0.1667 & 34.35 \\
\hline $\begin{array}{c}\text { Hangzhou Electronic Science and } \\
\text { Technology University }\end{array}$ & 1.56 & 9 & 0.3400 & 74.31 \\
\hline Zhejiang University of Technology & 1.229 & 35 & 0.0698 & 84.37 \\
\hline $\begin{array}{c}\text { Zhejiang University of Science and } \\
\text { Technology }\end{array}$ & 1 & 10 & 0.1818 & 41.68 \\
\hline Ningbo University & 1.286 & 7 & 0.3214 & 33.62 \\
\hline Zhejiang A\&F University & 1 & 8 & 0.2500 & 23.08 \\
\hline Wenzhou Medical College & 1.818 & 11 & 0.5758 & 33.16 \\
\hline $\begin{array}{c}\text { Zhejiang Chinese Medical } \\
\text { University }\end{array}$ & 1.5 & 2 & 1.0000 & 25.60 \\
\hline
\end{tabular}

\section{SPSS analysis of patent cooperation network in university-industry-research collaboration upon the innovation performance of university}

In the era of knowledge economy, the innovative ability of a country is the key factor to decide the country's position in the competition around the world, and the innovation-driven development becomes the inevitable trend of world economic development. Universities, as one of the key compositions of technical innovation system, necessarily shoulder the historical mission.Innovation performance of universities is the comprehensive reflection of the university innovation ability and motivation, referring to the output of science and technology and the transformation of scientific and technological achievements in a certain period of time.

In this paper, we select ten universities' situation of applying for patent with external institutions jointly as samples of patent cooperation network in university-industry-research collaboration in Zhejiang province in 2013, select scores of the innovation performanceof these universities as quantitative data, and conduct the regression analysis through SPSS software to analyze quantificationally the influence of the patent cooperation network on innovation of universities. We select the university innovation performance as the dependent variable, cooperation depth, cooperation breadth and network density of the patent cooperation network as the independent variable to conduct regression analysis through SPSS to analyze the influence among the variables.

$\mathrm{R} \wedge 2$ said the proportioninterpreted by a regression equation in a total change of dependent variable university innovation performance. It can be seen from the table 2 that $\mathrm{R}^{\wedge} 2=0.903$, close to 1 , showing that cooperation depth, cooperation breadth and network density of patent cooperation networkexplain $90.3 \%$ of variation in the university innovation performance, and that the fitting degree of regression straight line on the observed value is fairly good.As a result, the regression equation explains well the influence of cooperation depth, breadth, network density on the innovation performance of universities.

Table 2 Model Summary ${ }^{\mathrm{b}}$

\begin{tabular}{|l|l|l|l|l|l|l|}
\hline Model & $\mathrm{R}$ & $\mathrm{R}$ Square & $\begin{array}{l}\text { Adjusted } \\
\text { Square }\end{array}$ & $\mathrm{R}$ & $\begin{array}{l}\text { Std. Error of the } \\
\text { Estimate }\end{array}$ & Durbin-Watson \\
\hline 1 & $.950^{\mathrm{a}}$ & .903 & .855 & 15.16288 & 1.848 \\
\hline
\end{tabular}

a. Predictors: (Constant), network density, cooperation depth, cooperation breadth

b. Dependent Variable: innovation performance 
In the table 3 , Sig. $=0.083$. The original hypothesis is: $\mathrm{H} 0: \beta 1=\beta 2=\ldots=\beta \mathrm{k}=0$ (all independent variable coefficient is 0 , namely there is no effect of cooperation depth, breadth and network density on the innovation performance). Sig. $=0.083<0.1$, the null hypothesis is not established, saying that at least one of three variables cooperation depth, breadth and network density have an impact on innovation performance of universities.

Table 3 ANOVA ${ }^{\mathrm{b}}$

\begin{tabular}{|ll|l|l|l|l|l|}
\hline Model & & Sum of Squares & df & Mean Square & F & Sig. \\
\hline 1 & Regression & 2526.562 & 3 & 842.187 & 3.663 & $.083^{\mathrm{a}}$ \\
& Residual & 1379.478 & 6 & 229.913 & & \\
& Total & 3906.040 & 9 & & & \\
\hline
\end{tabular}

a. Predictors: (Constant), network density, cooperation depth, cooperation breadth

b. Dependent Variable: innovation performance

In the table 4, the depth of cooperation, the regression equation of effect of cooperation depth, breadth and network density on the innovation performance is

$$
\mathrm{Y}=28.159+4.181 \mathrm{X} 1-3.396 \mathrm{X} 2+9.886 \mathrm{X} 3
$$

Regression coefficient values are large, showing that the selected independent variables have a significant impact on innovation performance of universities. In the regression equation, coefficients ofcooperation depth X1, cooperation breadth X2, network density X3 arerespectively 4.181, 3.396 and 9.886, concluding that the innovation performance and the cooperation depth, network density are positively correlated, and that the innovation performance and the cooperation breadth are negatively correlated, and the correlation betweeninnovation performance andnetwork density is slightly high.Therefore, it is suggested that universities should make great efforts to strengthen the depth of cooperation with other members of the network and should increase cooperation network density, andshould prevent the patent cooperation network members from overflowing.

Assumption corresponding to sig. at the back of each independent variable is $\mathrm{H} 0$ : $\beta \mathrm{i}=0$ ( $\beta \mathrm{i}$ : the coefficient of influence of independent variable on the dependent variable).Sig. value is less than 0.05 , so we reject the null hypothesis, saying that there is a great effect of the independent variable on the dependent variable. Sig. value is greater than 0.05 , so we accept the null hypothesis, saying that there is no significant effect of the independent variable on the dependent variable. Only the network density's sig. value is less than 0.05, indicating that there is the most effect of network density on innovation performance of universities, and the effect of cooperation depth and breadth on innovation performance of universities is little, which conforms to the above analysis on regression coefficient of the regression equation.

Table 4 Coefficients ${ }^{\mathrm{a}}$

\begin{tabular}{|l|l|l|l|l|l|}
\hline \multirow{2}{*}{ Model } & \multicolumn{2}{|l|}{ Unstandardized Coefficients } & Standardized Coefficients & & \\
\cline { 2 - 5 } & $\mathrm{B}$ & Std. Error & Beta & $\mathrm{t}$ & Sig. \\
\hline 1 (Constant) & 28.159 & 15.872 & & 1.774 & .021 \\
cooperation depth & 4.181 & 3.713 & 2.154 & 1.126 & .083 \\
cooperation breadth & -3.396 & 4.648 & -1.452 & -.730 & .126 \\
network density & 9.886 & 24.737 & .129 & .400 & .042 \\
\hline
\end{tabular}

a. Dependent Variable: innovation performance

We determine whether there exists singular value according to the absolute value of the general standardized residuals. At first,we test the independence and randomness of the residual sequence by D.W (Durbin - Watson) value and the Scatterplot chart. In the table 2, D.W $=1.848$, so we can calculate $\rho=0.076$ according to $D . W=2(1-\rho)$.The absolute value of $\rho$ is less than 0.3 , saying that there is the weak correlation among residuals, so regression equation basicallyoutlines the change of 
the dependent variable. Therefore the residual sequence passes the independence test. In the Fig.1, scatters are distributed up and down the straight line which the standard residual value equals to 0 randomly, and it can be seen the mean is zero from the distribution roughly. So the residual sequence passes the randomness test. Then we determine whether there exist singular values.Generally the absolute value of the standardized residual is more than 3 , showing the corresponding sample points can be thought of as singular values. The absolute value of the standardized residuals is less than 3 , showing there is no singular value to exist. In the residuals statistics table, the minimum of standardized residuals value is 1.140 , the maximum value is 1.972 , and the mean is 0 , which reflect all absolute values of standardized residual are less than 3 , so there is no singular value to exist.

Table 5 Residuals Statistics ${ }^{\mathrm{a}}$

\begin{tabular}{|l|l|l|l|l|l|}
\hline & Minimum & Maximum & Mean & Std. Deviation & $\mathrm{N}$ \\
\hline Predicted Value & 24.0259 & 84.2471 & 43.9190 & 16.75497 & 10 \\
Residual & -17.28649 & 29.89458 & .00000 & 12.38044 & 10 \\
Std. Predicted & -1.187 & 2.407 & .000 & 1.000 & 10 \\
Value & & & & & \\
Std. Residual & -1.140 & 1.972 & .000 & .816 & 10 \\
\hline
\end{tabular}

a. Dependent Variable: innovation performance

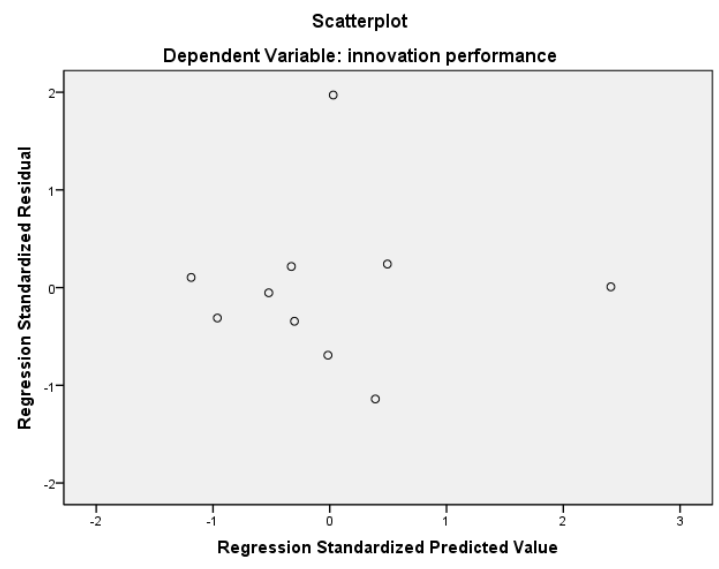

Fig.1. Scatter plot

\section{Summary}

In this paper, We analyze the influence of cooperation depth, breadth and network density of patent cooperation network on universities' innovation performance to conclude that cooperationdepthand network density have a positive effect on innovation performance of colleges and universities, and cooperation breadth negatively relate with innovation performance, so colleges and universities should make great efforts to strengthen the depth of cooperation with other members of the network, increase cooperation network density, at the same time prevent the patent cooperation network members from overflowing.And the influence of network density is the largest, so it is suggested that colleges and universities should pay more attention to the strengthening of network density.

\section{Acknowledgements}

The study is supported by Beijing Key Laboratory of Intelligent Logistics System, (BZ0211), and the construction of a teaching body- the promotion of teaching- the construction of virtual teaching team in double cultivation plan (municipal) (No.03516009011003), and Beijing Intelligent Logistics System Collaborative Innovation Center. 


\section{Reference}

[1] Yoo-JinHan, YongtaePark. Patent network analysis of inter-industrial knowledge flows: The case of Korea between traditional and emerging industries[J]. World Patent Information, 2006,(28): 235-247.

[2] Hsing-fenLe•MarcelaMiozzo. How does working on university-industry collaborative[J].The Journal of Technology Transfer, 2014.

[3] CHRISTIAN STERNITZKE. The international preliminary examination of patent applications filed under the Patent Cooperation Treaty - a proxy for patent value[J].Scientometrics, Vol. 78, 2009,(2): 189-202.

[4] Sam Mil'shtein. Development of Student Innovation Skills through Industry-University-Research Collaboration [J].Microwave Symposium Digest, 2009:233 - 236.

[5] Xiao Yu, Suli Zheng, Wei Wu. Research on the characteristics of development of cooperation patents inlocal universities and theintegrating degree with advantage discipline - on the basis of university-industry-research collaboration perspective [J]. Higher engineering education research, 2016(1):76-81.

[6] Zhejiang department of science.Notification of evaluation results on the innovation performance of provincial colleges and universities, research institutes by science and technology department in Zhejiang

province[EB/OL].2014[2016-5-18].http://www.zjkjt.gov.cn/news/node01/detail0101/2014/0101_49 910.htm.

[7] Zhi Xu, JiepingFan. Research on distribution characteristics of effective patents applied by university-enterprise jointly in China [J].Science and technology management, 2012, 1(33):36-40.

[8] Lijun Wang, Xin Gu. Study on the formation and evolution of regional innovative system [J]. Scientific and technological progress and countermeasures, 2012, 17:33-36.

[9] ShishiTu, Zhen Jia. Analysis of local social network structure and relationship on the basis of Tweet [J]. Guangxi science, 2013,1:75-78.

[10] Barabosi A. Statistical mechanics of complex networks [J]. Rev Mod Phys, 2002, 74(1):47-97. 